\title{
Current Practice of State-of-the-Art Coronary Revascularization in Patients with Heart Failure
}

Sérgio Costa Rayol ${ }^{1,2}$, MD; Michel Pompeu Barros Oliveira Sá ${ }^{1,2,3}$, MD, MSc, PhD; Luiz Rafael Pereira Cavalcanti ${ }^{1,2}$, MD; Felipe Augusto Santos Saragiotto ${ }^{1,2}$, MD; Roberto Gouvea Silva Diniz ${ }^{1,2}$, MD; Frederico Browne Correia de Araújo e Sá1,2, MD; Alexandre Motta de Menezes ${ }^{1,2}$, MD; Ricardo Carvalho Lima ${ }^{1,2,3}$, MD, MSc, PhD, ChM, AATS

\begin{tabular}{c|c|c|c|}
\multicolumn{2}{c}{ Scenario } & Evidence & Striking a balance between... \\
$\rightarrow$ Impaired LV function \\
$\rightarrow$ Ischemic heart disease \\
$\rightarrow$ Substantial viable myocardium \\
\hline$\rightarrow$ Improvement of LVEF
\end{tabular}

'Division of Cardiovascular Surgery, Pronto-Socorro Cardiológico de Pernambuco (PROCAPE), Recife, Brazil.

Universidade de Pernambuco (UPE), Recife, PE, Brazil.

${ }^{3}$ Nucleus of Postgraduate Studies and Research in Health Sciences of Faculdade de Ciências Médicas and Instituto de Ciências Biológicas (FCM/ICB), Recife, PE, Brazil.

\section{This study was carried out at the Department of Cardiovascular Surgery, Pronto-} Socorro Cardiológico de Pernambuco (PROCAPE), Recife, PE, Brazil.
No conflict of interest.

\section{Correspondence Address:}

Michel Pompeu Barros Oliveira Sá

(iD) http://orcid.org/0000-0001-5356-2996

Pronto-Socorro Cardiológico de Pernambuco (PROCAPE)

Rua dos Palmares, S/N - Santo Amaro - Recife, PE, Brazil - Zip code: 74970-240

E-mail:michel_pompeu@yahoo.com.br Article accepted on January 10 2019. 


\begin{abstract}
The best treatment for patients with ischemic heart failure (HF) is still on debate. There is growing evidence that coronary artery bypass graft (CABG) benefits these patients. The current recommendations for revascularization in this context are that CABG is reasonable when it comes to decreasing morbidity and mortality rates for patients with severe left ventricular dysfunction (ejection fraction $<35 \%$ ), and significant coronary artery disease (CAD) and should be considered in patients with operable coronary anatomy, regardless whether or not there is a viable myocardium (class IIb). Percutaneous coronary intervention (PCl) does not have enough data to allow the panels to reach a conclusion. The Korean Acute Heart Failure registry (KorAHF) had its data released recently, showing that patients with acute HF who underwent CABG had lower death rates, more complete revascularization
\end{abstract}

and less adverse outcomes compared with patients treated with $\mathrm{PCI}$. Recent ESC/EACTS guidelines on myocardial revascularization clearly recommended CABG as the first choice of revascularization strategy in patients with multivessel disease and acceptable surgical risk to improve prognosis in this scenario of left ventricular dysfunction. However, a high peri-procedural risk must be compared with the benefit of late mortality, and pros and cons of each strategy (either $\mathrm{PCl}$ or CABG) must be weighed in the decision-making process. Spurred on by the publication of the above-mentioned article and the release of new guidelines, we went on to write an overview of the current practice of state-ofthe-art coronary revascularization options in patients with HF.

Keywords: Coronary Artery Bypass. Stents. Percutaneous Coronary Intervention. Heart Failure.

\begin{tabular}{ll}
\hline Abbreviations, acronyms \& symbols \\
\hline AHF & $=$ Acute heart failure \\
CABG & $=$ Coronary artery bypass graft \\
CAD & $=$ Coronary artery disease \\
DES & $=$ Drug-eluting stent \\
EACTS & $=$ European Association for Cardio-Thoracic Surgery \\
ESC & $=$ European Society of Cardiology \\
HF & $=$ Heart failure \\
KorAHF & $=$ Korean Acute Heart Failure registry \\
LAD & $=$ Left anterior descending artery \\
LM & $=$ Left main \\
LVEF & $=$ Left ventricular ejection fraction \\
PCI & $=$ Percutaneous coronary intervention \\
\end{tabular}

\section{INTRODUCTION}

Recently, Lee et al. ${ }^{[1]}$ report data from the Korean Acute Heart Failure registry (KorAHF), which is a prospective, multicentre cohort study, aiming to compare coronary artery bypass graft $(\mathrm{CABG})$ and percutaneous coronary intervention $(\mathrm{PCl})$ in patients with acute heart failure (AHF) (propensity score matched).

Some interesting findings were:

1. The rate of death from any cause over 4 years was lower by $40 \%$ among patients who underwent CABG than among those who received $\mathrm{PCl}$;

2. In the overall cohort, CABG was associated with lower left ventricular ejection fraction (LVEF) and severe coronary lesions and the characteristics of the patients in the matched cohort were similar to those of CABG group in the overall cohort;

3. The complete revascularization rate, defined as all stenotic main-branch vessels being revascularized, was significantly higher in the CABG group than in the $\mathrm{PCl}$ group in the matched cohort;

4. Although the characteristics of the matched population were similar to those of the CABG group in the overall cohort, adverse outcomes were significantly lower in the CABG group than in the $\mathrm{PCl}$ group, especially in older patients, those with significant proximal left anterior descending (LAD) artery disease, and those without left main (LM) coronary artery disease (CAD) or chronic total occlusion, the trends favored CABG than PCl.

Spurred on by the publication of the above-mentioned article and the release of new guidelines, we went on to write an overview of the current practice of state-of-the-art coronary revascularization options in patients with $\mathrm{HF}$.

\section{What are the Current Guidelines for Revascularization in the Context of HF?}

Recent European Society of Cardiology (ESC) and European Association for Cardio-Thoracic Surgery (EACTS) guidelines on myocardial revascularization ${ }^{[2]}$ clearly recommended CABG as the first choice of revascularization strategy in patients with multivessel disease and acceptable surgical risk to improve prognosis in this scenario of left ventricular dysfunction (Table 1).

According to US guidelines ${ }^{[3,4]}$, revascularization strategies might be beneficial in the context of left ventricular dysfunction (Table 2). CABG surgery would be class of recommendation Ila for those with moderate left ventricular dysfunction and IIb for those with LVEF $\leq 35 \%$ without significant LM CAD. PCI does not have enough data to allow the panels to reach any conclusion nor make any recommendation.

\section{What About the Evidence in Other Studies?}

One of the first pieces of evidence was the Heart Failure Revascularization (HEART) trial[5], which enrolled 138 patients with HF, CAD and a LVEF $\leq 35 \%$, who had a substantial volume of viable myocardium with contractile dysfunction, assessed by any standard imaging technique, randomly assigned to a strategy of conservative management versus angiography with the intent of $\mathrm{PCl}$ or CABG. After a median follow-up of 59 months, there were $25(37 \%)$ deaths in those assigned to the conservative strategy, and 26 (38\%) in those assigned to the invasive strategy, 13 (29\%) of whom were revascularized. However, this study was underpowered and, further, larger trials were required to settle this issue. 
Table 1. European guideline-driven recommendations in the context of heart failure.

2018 ESC/EACTS Guidelines on myocardial revascularization

Recommendations on revascularizations in patients with chronic heart failure and systolic left ventricular dysfunction (ejection fraction $\leq 35 \%)$

\begin{tabular}{l|c|c}
\hline Recommendations & $\begin{array}{c}\text { Class of } \\
\text { recommendation }\end{array}$ & $\begin{array}{c}\text { Level of } \\
\text { evidence }\end{array}$ \\
\hline $\begin{array}{l}\text { In patients with severe left ventricular systolic dysfunction and CAD suitable for } \\
\text { intervention, myocardial revascularization is recommended }\end{array}$ & I & I \\
\hline $\begin{array}{l}\text { CABG is recommended as the first revascularization strategy choice in patients with } \\
\text { multivessel disease and acceptable surgical risk }\end{array}$ & Ila & B \\
\hline $\begin{array}{l}\text { In patients with one- or two-vessel disease, PCl should be considered as an alternative } \\
\text { to CABG when complete revascularization can be achieved }\end{array}$ & Ila \\
\hline $\begin{array}{l}\text { In patients with three-vessel disease, PCI should be considered based on the evaluation } \\
\text { by the Heart Team of the patient's coronary anatomy, the expected completeness of } \\
\text { revascularization, diabetes status and comorbidities }\end{array}$ & C \\
\hline $\begin{array}{l}\text { Left ventricular aneurysmectomy during CABG should be considered in patients with } \\
\text { NYHA class III/IV, large left ventricular aneurysm, large thrombus formation, or if the } \\
\text { aneurysm is the origin of arrhythmias }\end{array}$ & Ila \\
\hline $\begin{array}{l}\text { Surgical ventricular restoration during CABG may be considered in selected patients } \\
\text { treated in centers with expertise }\end{array}$ & IIb \\
\hline
\end{tabular}

$\mathrm{CAD}=$ coronary artery disease; $\mathrm{CABG}=$ coronary artery bypass graft; $\mathrm{NYHA}=$ New York Heart Association; $\mathrm{PCl}=$ percutaneous coronary intervention

The Alberta Provincial Project for Outcome Assessment in Coronary Heart Disease (APPROACH) ${ }^{[6]}$ compared the outcomes of patients propensity matched to obtain comparable subgroups with $C A D$ and left ventricular dysfunction undergoing $C A B G$ $(n=718)$ versus $P C I(n=718)$. The analysis identified that CABG was significantly associated with lower rates of repeat revascularization and better survival compared with $\mathrm{PCl}$ at 1,5,10 and 15 years.

The CREDO-Kyoto PCI/CABG Registry Cohort-2 ${ }^{[7]}$ identified 3,584 patients with 3-vessel and/or left main disease of 15,939 patients undergoing first myocardial revascularization, and 908 with LVEF <50\%. In both patients with moderate and severe left ventricular systolic dysfunction, the risk of cardiac death after $\mathrm{PCl}$ was significantly greater than after CABG. Similarly, the risk of allcause death tended to be higher after PCI than after CABG in both patients with moderate and severe left ventricular systolic dysfunction. CABG was associated with better 5-year survival outcomes than $\mathrm{PCl}$ in patients with LVEF $<50 \%$ with complex CAD in the era of drug-eluting stents.

In the Surgical Treatment Ischemic Heart Failure (STICH) tria|[8], 1,212 patients with CAD and LVEF $\leq 35 \%$ were randomized to medical therapy or CABG. Patients with LM disease were excluded, $17 \%$ of patients on medical therapy underwent CABG and $6 \%$ of patients underwent $\mathrm{PCl}$ by the end of the follow-up period. In the intention-to-treat analysis, all-cause mortality was not significantly lower with CABG than with medical therapy; however, all-cause mortality or hospitalization for cardiovascular causes occurred less frequently among patients undergoing CABG. The results with respect to all other secondary clinical outcomes also favored CABG. In addition, CABG was associated with a reduced risk for the primary outcome (death) in the "as-treated" analysis, which compared the outcomes of 592 patients treated with medical therapy throughout the first year after randomization with those of 620 patients who underwent CABG - either as a consequence of randomization or crossover-and reported significantly lower all-cause mortality in favor of CABG.

In 2016, the authors reported the results of the STICH Extension Study (STICHES) ${ }^{[9]}$, which was conducted to evaluate the long-term effects of CABG in patients with ischemic cardiomyopathy. The rate of death from any cause over 10 years was lower by $16 \%$ among patients who underwent CABG in addition to receiving medical therapy than among those who received medical therapy alone. Overall, CABG was associated with an incremental median survival benefit of nearly 18 months and prevention of one death due to any cause for every 14 patients treated and of one death due to a cardiovascular cause for every 11 patients treated. CABG was associated with more favorable results than isolated medical therapy across all clinically relevant long-term outcomes evaluated by the authors. These findings were directionally similar to those reported earlier. The choice between CABG and PCI should be made by the heart team after careful evaluation of the patient's clinical status and coronary anatomy, including SYNTAX Score, comorbidities and expected completeness of revascularization. A specialist in heart failure should be consulted.

Because $\mathrm{PCl}$ has become an established treatment option for selected patients with CAD and the STICH trial did not include a $\mathrm{PCl}$ arm, some groups sought to assess the comparative effectiveness of CABG versus $\mathrm{PCl}$ among patients with reduced 
Table 2. American guideline-driven recommendations in the context of heart failure.

ACC/AATS/AHA/ASE/ASNC/SCAI/SCCT/STS 2017 Appropriate Use Criteria for Coronary Revascularization in Patients with Stable Ischemic Heart Disease

Revascularization to improve survival compared with medical therapy in the anatomic setting of left ventricular dysfunction

\begin{tabular}{l|c|c}
\hline Recommendations & $\begin{array}{c}\text { Class of } \\
\text { recommendation }\end{array}$ & $\begin{array}{c}\text { Level of } \\
\text { evidence }\end{array}$ \\
\hline CABG - ejection fraction 35\% to 50\% & Ila & B \\
\hline CABG - ejection fraction $<35 \%$ without significant left main CAD & Ilb & $\mathrm{B}$ \\
\hline$P C l$ & Insufficient data & N/A \\
\hline
\end{tabular}

2013 ACCF/AHA Guideline for the Management of Heart Failure: Executive Summary - Recommendations for Stage C HFpEF Updated in 2017

\begin{tabular}{|c|c|c|}
\hline Recommendations & $\begin{array}{l}\text { Class of } \\
\text { recommendation }\end{array}$ & $\begin{array}{l}\text { Level of } \\
\text { evidence }\end{array}$ \\
\hline $\begin{array}{l}\text { CABG or PCl is indicated for HF patients on GDMT with angina and suitable coronary } \\
\text { anatomy, especially significant left main stenosis or left main equivalent }\end{array}$ & I & C \\
\hline $\begin{array}{l}\text { CABG to improve survival is reasonable in patients with mild to moderate left ventricular } \\
\text { systolic dysfunction and significant multivessel CAD or proximal LAD stenosis when } \\
\text { viable myocardium is present }\end{array}$ & Ila & B \\
\hline $\begin{array}{l}\text { CABG is reasonable to improve morbidity and mortality for patients with severe left } \\
\text { ventricular dysfunction (ejection fraction }<35 \% \text { ) and significant CAD }\end{array}$ & Ila & B \\
\hline $\begin{array}{l}\text { CABG may be considered in patients with ischemic heart disease, severe left ventricular } \\
\text { systolic dysfunction and operable coronary anatomy, regardless of whether a viable } \\
\text { myocardium is present }\end{array}$ & Ilb & B \\
\hline
\end{tabular}

$C A D=$ coronary artery disease; $C A B G=$ coronary artery bypass graft; GDMT=guideline-directed medical therapy; $L A D=$ eft anterior descending artery; $\mathrm{PCl}=$ percutaneous coronary intervention

ventricular function and multivessel CAD. For example, the Northern New England Cardiovascular Disease Study Group (NNECDSG) ${ }^{[10]}$ is a voluntary regional consortium of 7 hospitals in New Hampshire, Vermont, and Maine that provide the majority of $\mathrm{PCl}$ and cardiac surgery in the region. The authors examined all patients undergoing primary isolated coronary revascularization from 2004 to 2014. To simulate a real-world STICH-like population, the inclusion and exclusion criteria for the STICH trial were applied. Specifically, were included in the analysis patients who had $E F \leq 35 \%$ and 2- or 3-vessel CAD. The final study cohort was 955 CABG and $718 \mathrm{PCl}$ patients. The median duration of follow-up was 4.3 years. CABG was associated with improved long-term survival compared to $\mathrm{PCl}$ after risk adjustment. Although $C A B G$ and $\mathrm{PCl}$ had similar 30-day mortality rates, CABG was associated with a higher frequency of cerebrovascular accidents and acute kidney injury, whereas PCI was associated with a higher incidence of repeat revascularization. The authors concluded that, among patients with reduced ejection fraction and multivessel disease, CABG was associated with improved long-term survival compared with $\mathrm{PCl}$ and should be strongly considered in patients with ischemic cardiomyopathy and multivessel coronary disease.

\section{Could PCI Provide Comparable Outcomes to CABG in Patients with HF?}

Yang et al. ${ }^{[11]}$ enrolled patients with reduced left ventricular systolic function, defined as a LVEF $<50 \%$, who had PCI with drug-eluting stent (DES) or CABG from the Cardiovascular Catheterization and Surgery Databases of Samsung Medical Center. There was no statistically significant difference in allcause death in the follow-up (median duration of 32 months). In the propensity score matching analysis performed in 141 patient pairs, the long-term cumulative mortality rate was not significantly different between the groups. However, the rate of major adverse cardiac and cerebrovascular events was higher in the DES group than the CABG group, which was explained by the higher incidence of repeat revascularization in the DES group.

Bangalore et al. ${ }^{[12]}$ selected patients with multivessel disease and LVEF $\leq 35 \%$ who underwent either PCl with everolimuseluting stent $(n=1063)$ or CABG $(n=1063)$ with propensity score matching from the New York State Percutaneous Coronary Intervention Reporting System. In the short term, $\mathrm{PCl}$ was associated with a lower risk of stroke in comparison with CABG. At long-term follow-up (median of 2.9 years), PCI was associated with a similar risk of death, a higher risk of myocardial infarction, a 
lower risk of cerebrovascular accident, and a higher risk of repeat revascularization. Completeness of revascularization played a major role in this study, such that, in patients in whom complete revascularization was achieved with $\mathrm{PCl}$, there was no difference in myocardial infarction between $\mathrm{PCl}$ and $\mathrm{CABG}$.

\section{A Word of Caution}

Although it seems clear that patients with severe left ventricular dysfunction benefit most from revascularization, nothing is set in stone yet. A high peri-procedural risk must be balanced against late mortality benefit and pros and cons of each strategy (either $\mathrm{PCl}$ or $(\mathrm{ABG})$ must be weighed up in the decision-making process.

\section{Authors' roles \& responsibilities}

SCR Drafting the work or revising it critically for important intellectual content; final approval of the version to be published

MPBOS Substantial contributions to the conception or design of the work; or the acquisition, analysis, or interpretation of data for the work; agreement to be accountable for all aspects of the work in ensuring that questions related to the accuracy or integrity of any part of the work are appropriately investigated and resolved; final approval of the version to be published

LRPC Drafting the work or revising it critically for important intellectual content; agreement to be accountable for all aspects of the work in ensuring that questions related to the accuracy or integrity of any part of the work are appropriately investigated and resolved; final approval of the version to be published

FASS Drafting the work or revising it critically for important intellectual content; final approval of the version to be published

RGSD Drafting the work or revising it critically for important intellectual content; final approval of the version to be published

FBCAS Drafting the work or revising it critically for important intellectual content; agreement to be accountable for all aspects of the work in ensuring that questions related to the accuracy or integrity of any part of the work are appropriately investigated and resolved; final approval of the version to be published

AMM Drafting the work or revising it critically for important intellectual content; final approval of the version to be published

$\mathrm{RCL} \quad$ Drafting the work or revising it critically for important intellectual content; final approval of the version to be published

\section{REFERENCES}

1. Lee SE, Lee H-Y, Cho H, Choe WS, Kim H, Choi JO, et al. Coronary artery bypass graft versus percutaneous coronary intervention in acute heart failure. Heart. 2018 [In press].

2. Neumann FJ, Sousa-Uva M, Ahlsson A, Alfonso F, Banning AP, Benedetto U, et al., ESC Scientific Document Group. 2018 ESC/EACTS Guidelines on myocardial revascularization. Eur Heart J. 2019;40(2):87-165.

3. Yancy CW, Jessup M, Bozkurt B, Butler J, Casey DE Jr, Drazner MH, et al. 2013 ACCF/AHA Guideline for the management of heart failure: executive summary. A report of the American College of Cardiology Foundation/ American Heart Association Task Force on practice guidelines. Circulation. 2013;128(16):1810-52.

4. Fihn SD, Gardin JM, Abrams J, Berra K, Blankenship JC, Dallas AP, et al. 2012 ACCF/AHA/ACP/AATS/PCNA/SCAI/STS guideline for the diagnosis and management of patients with stable ischemic heart disease: a report of the American College of Cardiology Foundation/American Heart Association Task Force on Practice Guidelines, and the American College of Physicians, American Association for Thoracic Surgery, Preventive Cardiovascular Nurses Association, Society for Cardiovascular Angiography and Interventions, and Society of Thoracic Surgeons. J Am Coll Cardiol. 2012;60(24):e44-164.

5. Cleland JGF, Calvert M, Freemantle N, Arrow Y, Ball SG, Bonser RS, et al. The Heart Failure Revascularisation Trial (HEART). Eur J Heart Fail. 2011;13(2):227-33.

6. Nagendran J, Norris CM, Graham MM, Ross DB, Macarthur RG, KieserTM, et al. Coronary revascularization for patients with severe left ventricular dysfunction. Ann Thorac Surg. 2013;96(6):2038-44.

7. Marui A, Kimura T, Nishiwaki N, Mitsudo K, Komiya T, Hanyu M, et al. Comparison of five-year outcomes of coronary artery bypass grafting versus percutaneous coronary intervention in patients with left ventricular ejection fractions $\leq 50 \%$ versus $>50 \%$ (from the CREDO-Kyoto PCI/CABG Registry Cohort-2). Am J Cardiol. 2014;114(7):988-96.

8. Velazquez EJ, Lee KL, Deja MA, Jain A, Sopko G, Marchenko A, et al. Coronary-artery bypass surgery in patients with left ventricular dysfunction. N Engl J Med. 2011;364(17):1607-16.

9. Velazquez EJ, Lee KL, Jones RH, Al-Khalidi HR, Hill JA, Panza JA, et al. Coronary-artery bypass surgery in patients with ischemic cardiomyopathy. N Engl J Med. 2016;374(16):1511-20.

10. Iribarne A, DiScipio AW, Leavitt BJ, Baribeau YR, McCullough JN, Weldner PW, et al. Northern New England Cardiovascular Disease Study Group. Comparative effectiveness of coronary artery bypass grafting versus percutaneous coronary intervention in a real-world Surgical Treatment for Ischemic Heart Failure trial population. J Thorac Cardiovasc Surg. 2018;156(4):1410-21.

11. Yang JH, Choi SH, Song YB, Hahn JY, Choi JH, Jeong DS, et al. Long-term outcomes of drug-eluting stent implantation versus coronary artery bypass grafting for patients with coronary artery disease and chronic left ventricular systolic dysfunction. Am J Cardiol. 2013;112(5):623-9.

12. BangaloreS, Guo Y, Samadashvili Z, Blecker S, Hannan EL. Revascularization in patients with multivessel coronary artery disease and severe left ventricular systolic dysfunction: everolimus-eluting stents versus coronary artery bypass graft surgery. Circulation. 2016;133(22):2132-40. 